\title{
Five models of hysteretic water-retention capacity and their comparison for sandy soil
}

\author{
Vitaly Terleev ${ }^{1}$, Wilfried Mirschel $^{2}$, Aleksandr Nikonorov $^{1 *}$, Roman Ginevsky ${ }^{1}$, \\ Viktor Lazarev ${ }^{1}$, Alex Topaj ${ }^{3}$, Kirill Moiseev ${ }^{3}$, Kasim Layshev $^{4}$, Mikhail Arkhipov ${ }^{3,4}$, \\ Aleksandr Melnichuk ${ }^{5}$, Ielizaveta Dunaieva ${ }^{6}$, and Valentina Popovych ${ }^{6}$ \\ ${ }^{1}$ Peter the Great St.Petersburg Polytechnic University, Polytechnicheskaya, 29, St.Petersburg, 195251, \\ Russia \\ ${ }^{2}$ Leibniz-Centre for Agricultural Landscape Research, Eberswalder Straße 84, Müncheberg, 15374, \\ Germany \\ ${ }^{3}$ Agrophysical Research Institute, Grazhdanskii pr., 14, St. Petersburg, 195220, Russia \\ ${ }^{4}$ Fed. State Budgetary Inst. N.-W. Ctr. of Interdisc. Researches of Problems of Food Maintenance, \\ Podbelskogo shosse, 7, St. Petersburg-Pushkin, Russian Federation \\ ${ }^{5}$ V.I.Vernadsky Crimean Federal University, Vernadskogo pr., 4, Simferopol, Crimea, 295007, Russia \\ ${ }^{6}$ Federal State Budget Scientific Institution «Research Institute of Agriculture of Crimea», Kievskaya, \\ 150, Simferopol, Crimea, 295453, Russia
}

\begin{abstract}
A description of five mathematical models of the water-retention capacity of soil is given, taking into account the hysteresis phenomena. A computational experiment was carried out with these models using data on sandy soil. The experiment consisted of: (i) tuning of the models (parameter identification) by the method of dot-approximation of experimental data on the main drying and wetting branches of the hysteresis loop using an optimizing algorithm; (ii) the predictive calculation of the scanning branches of the hysteresis loop; (iii) a comparison of the errors in tuning results and the predictive calculation using the Williams-Kloot criteria. The commensurate and sufficiently low errors in the adjustment of the models have been achieved. The differences in the calculation of the scanning hysteresis branches are revealed. The practical significance of the mathematical models presented is to ensure the calculation of precision irrigation rates. The application of such rates in irrigation farming will help to prevent excess moisture from flowing beyond the root layer of the soil under the influence of gravity and, thus, to minimize the losses (unproductive consumption) of irrigation water, fertilizers, meliorants and plant protection products, and also reduce the risk of groundwater contamination with agrochemicals and eutrophication of water bodies.
\end{abstract}

\footnotetext{
* Corresponding author: coolhabit@yandex.ru
} 


\section{Introduction}

One of the most important indicators characterizing the hydrophysical properties of the soil is its water retention capacity. This indicator is usually described as a relationship between the volumetric water content $\theta\left[\mathrm{cm}^{3} \cdot \mathrm{cm}^{-3}\right]$ and the capillary pressure of soil moisture $\psi\left[\mathrm{cm} \mathrm{H}_{2} \mathrm{O}\right]$. Due to the hysteresis phenomena, the water-retention capacity curves, constructed from the measurements of soil drainage, do not coincide with the wetting curves. Direct measurement of water-retention capacity is a laborious process. Taking into account the multiplicity of the scanning branches filling the hysteresis loop of the water-retention capacity of the soil, measuring this index represents an almost insoluble problem. In this paper, a description of five mathematical models of the water-retention capacity hysteresis is described. The purpose of the work is to verify the presented models and compare them by the prediction error of scanning branches on the example of sandy soil.

In irrigation farming, the availability of the water-retention capacity of the soil data is an important condition for irrigation rates calculation. The simplest (but insufficiently accurate) method of this calculation is based on the use of the main drying branch data. This branch is usually measured by the press method, successively replacing water with pneumatic pressure from previously saturated moisture samples. A number of singular points separating the intervals of qualitatively different moisture states could be allocated from the experimental curve obtained by this method. Values $\theta$, corresponding to these points are called soilhydrological constants. Such constants include: field capacity (FC), the moisture of capillary break (CB), moisture of permanent wilting point (WP), maximum hygroscopy (MH). In irrigation agriculture, irrigation rate is often calculated by the difference in FC-CB or from the difference between FC and the pre-assumed volumetric water content. With this approach, a methodological error is quite obvious. Indeed, FC and CB are determined from the main drying branch, but in irrigation the change of moisture states in the soil is described not by the drying branch, but by the wetting branch. Therefore, using the drying branch for irrigation rate calculation leads to significant errors in the results of the calculation. Further, an explanation of the cause of these errors is offered.

The ability of soils to retain water is determined not by their moisture reserves, but by its capillary pressure. In other words, if the quantity $\theta$ reaches a value that corresponds to FC, this does not mean that moisture does not flow off the soil root layer. In accordance with the idea of the nature of the water-retention capacity, soil moisture is in a capillary-suspended state until a negative value $\psi$ does not exceed the value that corresponds to FC on the main drying branch. A feature of the water-retention capacity hysteresis is that the scanning wetting branches, which start from certain reversal points, are located below the main drying branch. Thus, if the estimated soil moisture is $\mathrm{CB}$, then under FC-CB the soil reaches a moisture content equal to $\mathrm{FC}$; but the value $\psi$ is higher than the value that corresponds to FC on the main drying branch; and excess moisture flows under the action of gravity beyond the root layer [1]. The authors do not propose to prove the negative nature of the applying excessive irrigation rates consequences (unproductive irrigation water consumption, washing out of nutrients and other agrochemicals in groundwater, etc.). It is more important to indicate the reason for overestimating the irrigation standards and to suggest ways to solve it.

Probably, this problem can be solved by using a predetermined and measured wetting branch in the calculation of irrigation rates. With this assumption, one can partially agree if irrigation farming is conducted in conditions that are protected from atmospheric precipitation. If the cultivation of crops is carried out in natural conditions, at the beginning of precipitation, soil moisture transfers from the states supposable described by the main drying branch, to the states described by the scanning (in this case, primary) wetting 
branches, starting from the reversal points, whose positions are not known in advance (the probable nature of the weather forecast). The end of precipitation leads to a transition to scanning (in this case - secondary) drying branches from the reversal points, the positions of which are also not known in advance. Hence, it becomes obvious that an unlimited number of measurements of the scanning branches of the hysteresis loop will be required in order to take into account possible scenarios of atmospheric soil moisture, which is practically impracticable. Thus, the only method of obtaining the necessary data is the method of mathematical modeling.

\section{Materials and Methods}

Literature data on the water-retention capacity of light granulometric composition soil Dune sand are used in the paper [2].

The concepts of pore size distribution, as well as capillary phenomena in pore space, appear to be very productive in modeling of the hydrophysical properties of soil [3]. Developing Kosugi's ideas [4, 5], the authors use the following formulas to describe the main drying branch of the soil WRC:

$$
\begin{aligned}
& d S_{\mathrm{e}} / d \psi=\left[\begin{array}{l}
\frac{-n}{4\left(\psi-\psi_{\mathrm{e}}\right)} \exp \left(-\left(\frac{n \sqrt{\pi}}{4} \ln \left(\frac{\psi-\psi_{\mathrm{e}}}{\psi_{0}-\psi_{\mathrm{e}}}\right)\right)^{2}\right), \psi<\psi_{\mathrm{e}} ; \\
0, \psi \geq \psi_{\mathrm{e}},
\end{array}\right. \\
& S_{\mathrm{e}}=\left[\begin{array}{l}
\frac{1}{2} \operatorname{erfq}\left(\frac{n \sqrt{\pi}}{4} \ln \left(\frac{\psi-\psi_{\mathrm{e}}}{\psi_{0}-\psi_{\mathrm{e}}}\right)\right), \psi<\psi_{\mathrm{e}} ; \\
1, \psi \geq \psi_{\mathrm{e}},
\end{array}\right.
\end{aligned}
$$

where; $S_{\mathrm{e}}=\left(\theta-\theta_{\mathrm{R}}\right)\left(\theta_{\mathrm{S}}-\theta_{\mathrm{R}}\right)-$ effective saturation; $\theta_{\mathrm{S}}\left[\mathrm{cm}^{3} \cdot \mathrm{cm}^{-3}\right]-$ saturated volumetric water content; $\theta_{\mathrm{R}}\left[\mathrm{cm}^{3} \cdot \mathrm{cm}^{-3}\right]-$ residual volumetric water content; $\psi_{\mathrm{e}}\left[\mathrm{cm} \mathrm{H}_{2} \mathrm{O}\right]$ - capillary pressure of soil moisture under air entrance condition (bubbling pressure); $\psi_{0}$ [ $\mathrm{cm} \mathrm{H}_{2} \mathrm{O}$ ] - capillary pressure, which corresponds to the most probable value of the random variable - the logarithm of the effective radius of the soil pore; $\sigma$ - the standard deviation of this random variable; $n=4 /(\sigma \sqrt{2 \pi}) ; \quad \operatorname{erfd}(z)=1-(2 / \sqrt{\pi}) \int_{0}^{z} \exp \left(-t^{2}\right) d t-$ the complementary error function.

If $\psi_{\mathrm{e}}=0$, so: approximation (2) is a model of Kosugi [4, 5]. In the paper [6], a description of the continuous approximation of relation (2) in the class of elementary functions is given:

$$
S_{\mathrm{e}} \approx\left[\begin{array}{l}
\left(1+\left(\frac{\psi-\psi_{\mathrm{e}}}{\psi_{0}-\psi_{\mathrm{e}}}\right)^{n}\right)^{-1}, \psi<\psi_{\mathrm{e}} ; \\
1, \psi \geq \psi_{\mathrm{e}} .
\end{array}\right.
$$

Approximation (3) is reduced to the model proposed in articles [7-9], but unlike this model, the approximation parameters (3) are physically interpreted.

As is known, one of the widely used models of water-retention capacity of the soil is the model proposed by Van Genuchten [10]: 


$$
S_{\mathrm{e}}=\left[\begin{array}{l}
\left(1+\left(\frac{\psi}{\psi_{0}}\right)^{n}\right)^{-(1-1 / n)}, \psi<0 ; \\
1, \psi \geq 0 .
\end{array}\right.
$$

It is easy to see that when $\psi_{\mathrm{e}}=0$ and $n>>1$ functions (3) and (4) practically coincide.

The assumption that the differential moisture capacity function is used in the hysteresis modeling $\mu(\psi)=\left(\theta_{\mathrm{S}}-\theta_{\mathrm{R}}\right) d S_{\mathrm{e}} / d \psi$ at each point on the hysteresis loop branches takes only two values corresponding to the sorption and desorption equilibrium of moisture. Therefore, two sets of parameters are used to describe the branches of the hysteresis loop: one set for all drying branches and one set for all wetting branches. Scanning (primary, secondary, etc.) branches start from reversal points, the calculation algorithm of which is proposed in [11]. On the basis of these concepts, we will now describe a set of five hysteresis models for the water-retention capacity of the soil.

The first model from the set is the Scott-Haverkamp model (WRC-SH), which is based on the function described by relation (3) when $\psi_{\mathrm{e}}=0[9,11]$. The second model from the set is an improved Scott-Haverkamp model (WRC-SH+), which is based on the function described by relation $(3)$ when $\psi_{\mathrm{e}} \neq 0[6,9,11]$. The third model from this set is the ScottKosugi model (WRC-SK), which is based on the function described by relation (2) when $\psi_{\mathrm{e}}=0[4,5,11]$. The fourth model from the set is an improved Scott-Kosugi model (WRC$\mathrm{SK}+$ ), which is based on the function described by the relation (2) when $\psi_{\mathrm{e}} \neq 0$ [4-6, 11]. The fifth model from the set is the Kool-Parker-Van Genuchten model, which is based on the function $[10,12]$, described by the relation (4).

The following parameters are used in the listed models: $\psi_{0, \mathrm{~d}}\left[\mathrm{~cm} \mathrm{H} \mathrm{H}_{2} \mathrm{O}\right], \psi_{\mathrm{e}, \mathrm{d}}\left[\mathrm{cm} \mathrm{H}_{2} \mathrm{O}\right.$ ] and $n_{\mathrm{d}}$ (for drying branches), as well as $\psi_{0, \mathrm{w}}\left[\mathrm{cm} \mathrm{H}_{2} \mathrm{O}\right], \psi_{\mathrm{e}, \mathrm{w}}\left[\mathrm{cm} \mathrm{H} \mathrm{H}_{2} \mathrm{O}\right]$ and $n_{\mathrm{w}}$ (for wetting branches). In the second and fourth models there are additional parameters $\psi_{\mathrm{e}, \mathrm{d}}$ (for drying branches) and $\psi_{\mathrm{e}, \mathrm{w}}$ (for wetting branches). Interpretation of these parameters was proposed in [6].

The following formulas are used to describe the drying branch, starting from the $\mathrm{i}$-th point on the wetting branch $[13,14]$ :

$$
\left\{\begin{array}{l}
{\left[\begin{array}{l}
\theta=\theta_{\mathrm{R}}+\left(\theta_{\mathrm{S}}^{*}-\theta_{\mathrm{R}}\right) S_{\mathrm{e}, \mathrm{d}} \\
\theta_{\mathrm{s}}^{*}=\theta_{\mathrm{s}}, \psi_{\mathrm{e}, \mathrm{w}} \leq \psi_{\mathrm{i}}, \psi<\psi_{\mathrm{e}, \mathrm{d}} \\
\theta_{\mathrm{s}}^{*}=\theta_{\mathrm{i}}, \psi_{\mathrm{e}, \mathrm{d}} \leq \psi_{\mathrm{i}}<\psi_{\mathrm{e}, \mathrm{w}}, \psi<\psi_{\mathrm{e}, \mathrm{d}} \\
\theta_{\mathrm{s}}^{*}=\frac{\theta_{\mathrm{i}}-\theta_{\mathrm{R}}\left(1-S_{\mathrm{e}, \mathrm{d}}\left(\psi_{\mathrm{i}}\right)\right)^{2}}{S_{\mathrm{e}, \mathrm{d}}\left(\psi_{\mathrm{i}}\right)}, \psi_{\mathrm{i}}<\psi_{\mathrm{e}, \mathrm{d}}, \psi \leq \psi_{\mathrm{i}}
\end{array}\right.} \\
{\left[\begin{array}{l}
\theta=\theta_{\mathrm{s}}, \psi_{\mathrm{e}, \mathrm{w}} \leq \psi_{\mathrm{i}}, \psi_{\mathrm{e}, \mathrm{d}} \leq \psi \leq \psi_{\mathrm{i}} \\
\theta=\theta_{\mathrm{i}}, \psi_{\mathrm{e}, \mathrm{d}} \leq \psi_{\mathrm{i}}<\psi \mathrm{e}, \mathrm{w}
\end{array}, \psi_{\mathrm{e}, \mathrm{d}} \leq \psi \leq \psi_{\mathrm{i}} .\right.}
\end{array}\right.
$$

The following formulas are used to describe the wetting branch, starting from the $j$-th point on the drying branch: 


$$
\left\{\begin{array}{l}
{\left[\begin{array}{l}
\theta=\theta_{\mathrm{R}}^{*}+\left(\theta_{\mathrm{S}}-\theta_{\mathrm{R}}^{*}\right) S_{\mathrm{e}, \mathrm{w}} ; \\
\theta_{\mathrm{R}}^{*}=\theta_{\mathrm{j}}=\theta_{\mathrm{r}}, \psi_{\mathrm{j}}<<\psi_{\mathrm{e}, \mathrm{d}}, \psi_{\mathrm{j}} \leq \psi<\psi_{\mathrm{e}, \mathrm{w}} ; \\
\theta_{\mathrm{R}}^{*}=\frac{\theta_{\mathrm{j}}-\theta_{\mathrm{S}} S_{\mathrm{e}, \mathrm{w}}\left(\psi_{\mathrm{j}}\right)}{1-S_{\mathrm{e}, \mathrm{w}}\left(\psi_{\mathrm{j}}\right)}, \psi_{\mathrm{j}}<\psi_{\mathrm{e}, \mathrm{d}}, \psi_{\mathrm{j}} \leq \psi<\psi \psi_{\mathrm{e}, \mathrm{w}}
\end{array}\right.} \\
{\left[\begin{array}{l}
\theta=\theta_{\mathrm{S}}, \psi_{\mathrm{j}}<\psi_{\mathrm{e}, \mathrm{d}}, \psi_{\mathrm{e}, \mathrm{w}} \leq \psi ; \\
\theta=\theta_{\mathrm{j}}=\theta_{\mathrm{s}}, \psi_{\mathrm{e}, \mathrm{d}} \leq \psi_{\mathrm{j}}, \psi_{\mathrm{j}} \leq \psi .
\end{array}\right.}
\end{array}\right.
$$

\section{Results}

A computer program called «Hysteresis» has been developed based on relations (1)-(6) in which: (i) the parameters of the above mentioned WRC hysteresis models are described; and (ii) the predictive calculation of the scanning branches of the hysteresis loop is held. Computational experiments were carried out using this program and experimental data on sandy soil Dune sand [2]. The first experiment consisted in tuning (identifying the parameters) of all models from data on the main branch of desiccation and the main branch of moistening of the soil under investigation. The parameters of the five compared models are shown in Table 1.

Table 1. Parameters for soil Dune sand models[2]: tuning is performed by both main hysteresis branches

\begin{tabular}{||l|l|c|c|c|c|c|c|c|c||}
\hline \multirow{2}{*}{} & \multicolumn{10}{|c||}{ Models parameters } \\
\cline { 2 - 10 } & $\theta_{\mathrm{R}}$ & $\theta_{\mathrm{S}}$ & $\psi_{\mathrm{e}, \mathrm{d}}$ & $\psi_{\mathrm{e}, \mathrm{w}}$ & $\psi_{0, \mathrm{~d}}$ & $\psi_{0, \mathrm{w}}$ & $n_{\mathrm{d}}$ & $n_{\mathrm{w}}$ \\
\hline 1 & WRC-SH & 0.0960 & 0.3028 & 0 & 0 & -33.65 & -19.84 & 8.421 & 4.082 \\
2 & WRC-SH+ & 0.0934 & 0.3010 & -19.82 & -3.594 & -33.68 & -19.99 & 3.170 & 3.298 \\
3 & WRC-SK & 0.0984 & 0.3015 & 0 & 0 & -33.61 & -19.79 & 8.287 & 3.983 \\
4 & WRC-SK+ & 0.0957 & 0.3002 & -19.76 & -3.576 & -33.59 & -19.92 & 3.104 & 3.191 \\
5 & WRC-KPVG & 0.0936 & 0.3024 & 0 & 0 & -33.10 & -18.28 & 8.655 & 4.411 \\
\hline
\end{tabular}

An example of the WRC-SK+ model setting up is shown in the Figure 1. With these parameters, predictive calculations of the hysteresis loop scanning branches were carried out. An example of a predictive calculation of the hysteresis loop scanning branches using the WRC-SK + model is shown in the Figures 2 and 3. With respect to the identification of parameters and predictive calculations, the errors in these calculations (square root of the average arithmetic squares of the calculation deviations results from the experimental data) are shown in the Table 2 . In this table, the minimum errors are highlighted by bold underlined font. Further, the statistical hypothesis about the absence of reliable differences between the compared models was tested. The verification was carried out using the Williams-Kloot criterion [15]. The results of this verification are given in Tables 3 and 4 . With respect to the identification of parameters from data on the main drying branch and the main wetting branch, the use of the Williams-Kloot criterion did not reveal significant differences. 


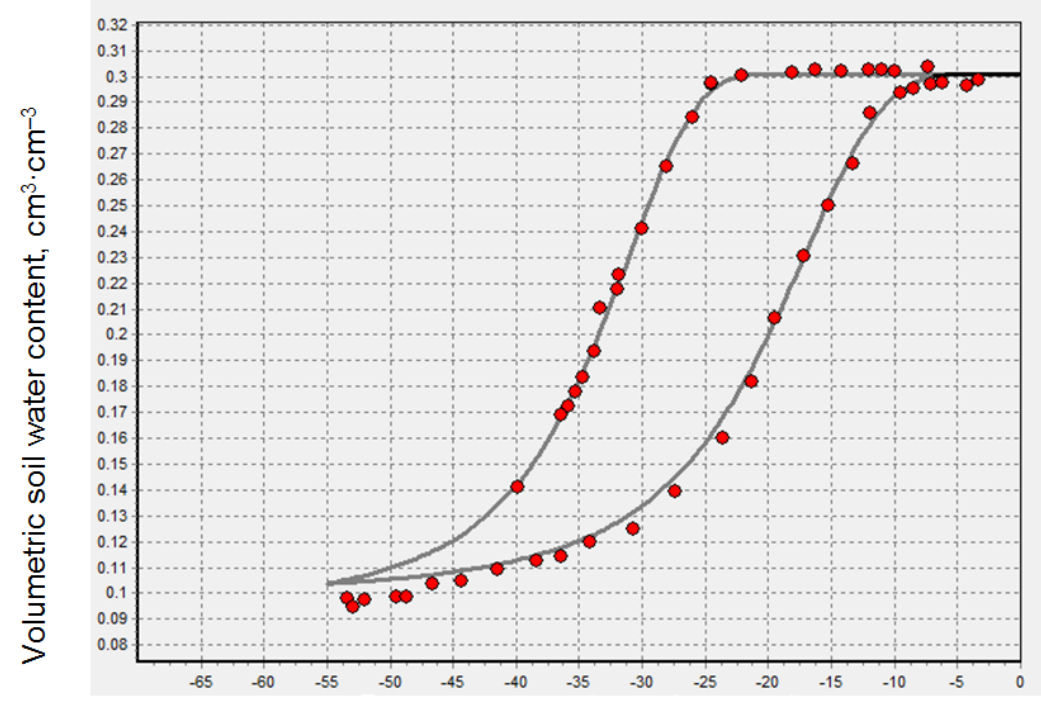

Capillary pressure of moisture (abs. value), $\mathrm{cm} \mathrm{H}_{2} \mathrm{O}$

Fig. 1. Main drying and main wetting branches of water-retention capacity of «Dune sand»: curves dot-approximation; points - measured data.

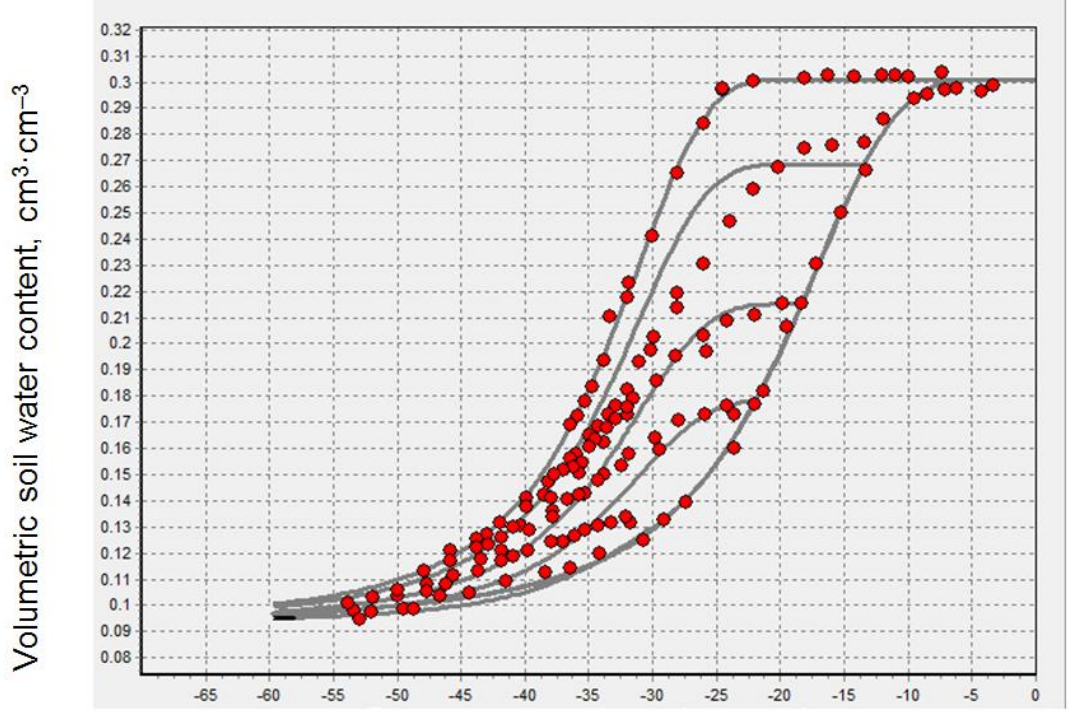

Capillary pressure of moisture (abs. value), $\mathrm{cm} \mathrm{H}_{2} \mathrm{O}$

Fig. 2. Scanning drying branches of water-retention capacity of «Dune sand»: curves - predictive calculation; points - measured data. 


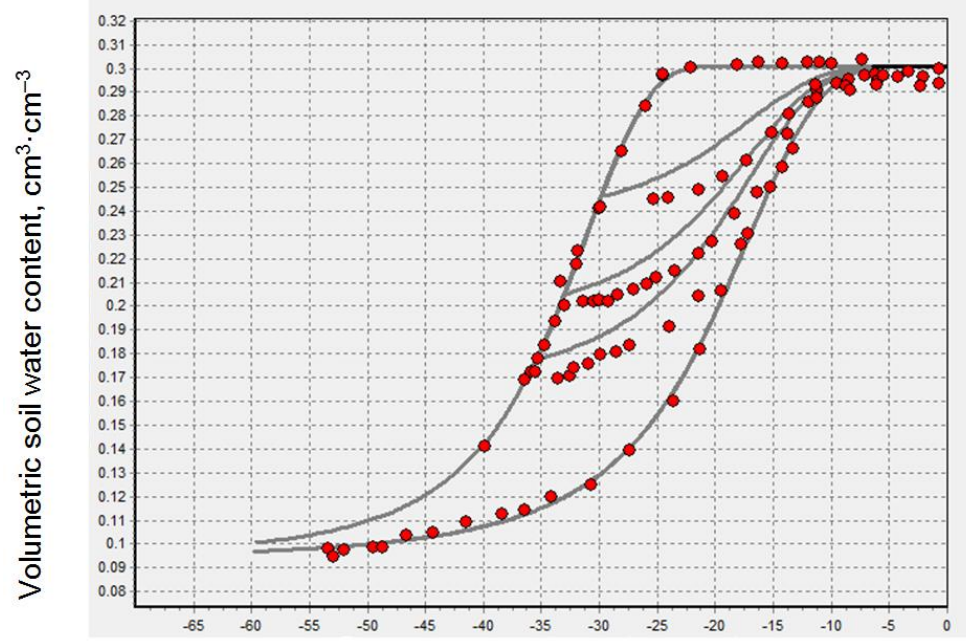

Capillary pressure of moisture (abs. value), $\mathrm{cm} \mathrm{H}_{2} \mathrm{O}$

Fig. 3. Scanning wetting branches of water-retention capacity of «Dune sand»: curves - predictive calculation; points - measured data.

Table 2. Comparison of the errors for the dot-approximation of the main branches and the predictive calculation of the scanning branches of the soil water-retention capacity

\begin{tabular}{|c|c|c|c|c|c|}
\hline & & & RMSE - root & an square error & \\
\hline & Models & $\begin{array}{l}\text { Parameters } \\
\text { identification } \\
\text { from main } \\
\text { branches data } \\
\text { (48 dots) }\end{array}$ & $\begin{array}{l}\text { Prediction od } \\
\text { drying scanning } \\
\text { branches } \\
\text { (95 dots) }\end{array}$ & $\begin{array}{l}\text { Prediction of } \\
\text { wetting scanning } \\
\text { branches } \\
\text { (47 dots) }\end{array}$ & $\begin{array}{l}\text { Prediction of all } \\
\text { scanning } \\
\text { branches } \\
\text { (142 dots) }\end{array}$ \\
\hline 1 & WRC-SH & 0.0033 & 0.0112 & 0.0091 & 0.0106 \\
\hline 2 & WRC-SH+ & $\underline{0.0026}$ & 0.0111 & 0.0083 & 0.0102 \\
\hline 3 & WRC-SK & 0.0032 & 0.0108 & 0.0089 & 0.0103 \\
\hline 4 & WRC-SK+ & 0.0029 & $\underline{0.0106}$ & $\underline{0.0081}$ & $\underline{0.0099}$ \\
\hline 5 & WRC-KPVG & 0.0032 & 0.0118 & 0.0088 & 0.0109 \\
\hline
\end{tabular}

Table 3. A comparison of the five functions of the soil water-retention capacity, using the WilliamsKloot criterion, based on the evaluation of all the scanning branches

\begin{tabular}{|c|c|c|c|c|c|c|c|c|c|c||}
\hline $\begin{array}{c}\text { Compa- } \\
\text { rable } \\
\text { models }\end{array}$ & $\begin{array}{c}1 \\
\text { and } \\
2\end{array}$ & $\begin{array}{c}1 \\
\text { and } \\
3\end{array}$ & $\begin{array}{c}1 \\
\text { and } \\
4\end{array}$ & $\begin{array}{c}1 \\
\text { and } \\
5\end{array}$ & $\begin{array}{c}2 \\
\text { and } \\
3\end{array}$ & $\begin{array}{c}2 \\
\text { and } \\
4\end{array}$ & $\begin{array}{c}2 \\
\text { and } \\
5\end{array}$ & $\begin{array}{c}3 \\
\text { and } \\
4\end{array}$ & $\begin{array}{c}3 \\
\text { and } \\
5\end{array}$ & $\begin{array}{c}4 \\
\text { and } \\
5\end{array}$ \\
\hline$\lambda$ & -0.64 & -4.90 & -0.98 & 8.15 & -0.04 & -5.33 & 1.43 & -0.75 & 5.77 & 1.46 \\
$\lambda_{0.95}$ & 0.64 & 1.63 & 0.49 & 1.90 & 0.71 & 1.44 & 0.62 & 0.59 & 1.16 & 0.47 \\
$\lambda_{0.975}$ & 0.76 & 1.94 & 0.59 & 2.27 & 0.84 & 1.72 & 0.74 & 0.71 & 1.39 & 0.56 \\
\hline Preferred & $1=2$ & 3 & 4 & 1 & $2=3$ & 4 & 2 & 4 & 3 & 4 \\
\hline
\end{tabular}




\section{Discussion}

From the analysis of the obtained results, it follows that, according to the Williams-Kloot criterion, all five models are statistically indistinguishable with respect to the error of dotapproximation of the experimental data on the main drying branch and the main wetting branch of the WRC hysteresis. It can be assumed that this result is due to the fact that the first and second models (WRC-SH and WRC-SH+) are continuous approximations of the third and fourth models (WRC-SK, WRC-SK+), respectively. At the same time, for sandy soil (for sufficiently large values of the parameters $n_{\mathrm{d}}$ and $n_{\mathrm{w}}$ ) the fifth model (WRC-KPVG) practically coincides with the first model (WRC-SH).

However, there is no reason to assert that the compared models are statistically indistinguishable with respect to the error in the predictive calculation of the scanning branches of the hysteresis loop. Table 3 shows that the fifth model is significantly inferior to the other four models. Of the ten combinations of pairwise comparison in four cases for the fourth model, in two cases for the third model, in one case for the second model and in one case for the first model is reliably more accurate. In this case, two compared pairs (the first and second models, as well as the second and third models) are statistically indistinguishable. The result can be explained as follows. A high error in the predictive calculation of the scanning hysteresis branches of the fifth model is due to the low adequacy of this model, since its parameters $\psi_{0, \mathrm{~d}}, \psi_{0, \mathrm{w}}, n_{\mathrm{d}}$ и $n_{\mathrm{w}}$ have no physical meaning. A low error in the predictive calculation of the scanning hysteresis branches of the fourth model is explained by the high adequacy of this model, since all its parameters are physically interpreted. The third model is somewhat inferior to the fourth model due to the lack of parameters $\psi_{\mathrm{e}, \mathrm{d}}$ and $\psi_{\mathrm{e}, \mathrm{w}}$ in the third model. This result confirms the expediency of using these parameters in modeling of the WRC hysteresis. The relative higher errors of the first and second models are evidently due to the fact that they, as noted above, are continuous approximations of the third and fourth models, respectively. The result of the statistical indistinguishability of the second and third models is interesting, from which it follows that the continuous approximation of the fourth model $\left(\psi_{\mathrm{e}, \mathrm{d}} \neq 0\right.$ and $\left.\psi_{\mathrm{e}, \mathrm{w}} \neq 0\right)$ and third model (without parameters $\psi_{\mathrm{e}, \mathrm{d}}$ and $\left.\psi_{\mathrm{e}, \mathrm{w}}\right)$ have commensurate errors in the predictive calculation of the scanning hysteresis branches.

Thus, it can be assumed that the use of the improved Scott-Kosugi model [4-6, 11] WRC$\mathrm{SK}+$ will be most effective in the modeling of the WRC of sandy soil for precise irrigation rates calculation. At the same time, if we take into account the simplicity of the functional description of the dependence $\theta(\psi)$ in the improved Scott-Haverkamp model $[6,9,11]$, as well as the second result of this model with respect to the error in the predictive calculation of the scanning hysteresis branches (see Table 2), then from the application of the WRC-SH+ model it is also possible to expect a fairly high efficiency in practical irrigation farming.

\section{Conclusions}

1. With respect to the error of the dot-approximation of the experimental data on the main drying branch and the main wetting branch of the WRC hysteresis, all five compared models (by the Williams-Kloot criterion) are statistically indistinguishable.

2. With respect to the error in the predictive calculation of the scanning hysteresis branches (according to the Williams-Kloot criterion): the fifth model is inferior to the four models; in the case of a paired comparison, in four cases for the fourth model, in two cases for the third model, in one case for the second model and in one case for the first model is reliably more 
accurate; The first and second models, as well as the second and third models, are statistically indistinguishable.

3. With respect to the predictive calculation of the scanning hysteresis branches, the high error of the fifth model is due to the fact that the parameters of this model $\psi_{0, \mathrm{~d}}, \psi_{0, \mathrm{w}}, n_{\mathrm{d}}$ and $n_{\mathrm{w}}$ have no physical meaning; The low error of the fourth model is explained by the adequacy of this model, all parameters of which are physically interpreted [6].

4. In the modeling of hysteresis, it is recommended to use the improved Scott-Kosugi model $[4-6,11]$, as well as the improved Scott-Haverkamp model $[6,9,11]$ for the calculation of precise irrigation rates for crops cultivated on sandy soils.

\section{Acknowledgements}

The research was supported by DAAD (PID: 91619700; A/10/01103) and Russian Foundation for Basic Research (\#16-04-01473-a; \#16-35-00059-mol_a).

\section{References}

1. V.V. Terleev, A.G. Topazh, W. Mirschel, Russian Meteorology and Hydrology, 40(4), 278-285 (2015).

2. R.W Gillham, A. Klute, D.F. Heermann, Soil Sci. Soc. Am. J., 40, 203-207 (1976).

3. E.H. D’Hollander, Water Resour. Res, 15, 107-112 (1979).

4. K. Kosugi, Water Resour. Res., 30, 891-901 (1994).

5. K. Kosugi, Water Resour. Res., 32, 2697-2703 (1996).

6. V. Terleev, W. Mirschel, V. Badenko, I. Guseva, P. Gurin, Agrofizika, 4(8), 1-8 (2012) (Rus).

7. W. Brutsaert, Soil Sci., 101, 85-92 (1966).

8. L.R. Ahuja, D. Swartzendruber, Soil Sci. Soc. Am. Proc., 36, 9-14 (1972).

9. R. Haverkamp, M. Vauclin, J. Touma, P.J. Wierenga, G. Vachaud, Soil Sci. Soc. Am. J., 41, 285-294 (1977)..

10. M.Th. Van Genuchten, Soil Science Society of America Journal, 44, 892-989 (1980).

11. P.S. Scott, G.J. Farquhar, N. Kouwen, Proceeding of National Conference on Advances in Infiltration, American Society of Agricultural Engineers, St. Joseph, Michigan, 163170 (1983).

12. J.B. Kool, J.C. Parker, Water Resources Research, 23(1), 105-114 (1987).

13. V.V. Terleev, A.O Nikonorov, R.S. Ginevsky, et.al., Magazine of Civil Engineering, 77(1), 141-148 (2018).

14. V. Terleev, R. Ginevsky, V. Lazarev, et.al. IOP Conference Series: Earth and Environmental Science, 90, Article ID 012105 (2017).

15. A.I. Kobzar. Izd. Fizmatlit, Moskva. 816 p (2006). (Rus). 